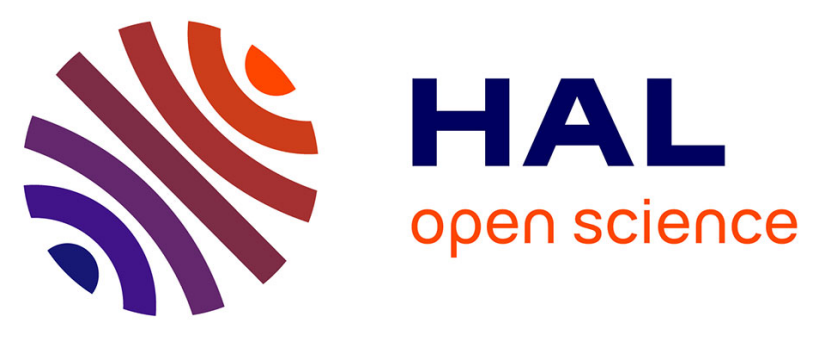

\title{
Synthesis, crystal structure and high-temperature transport properties of the new cluster compound Rb2Mo15Se19
}

Gilles Daigre, Patrick Gougeon, Philippe Gall, Régis Gautier, Olivier Guillou, Jean-Baptiste Vaney, Christophe Candolfi, Anne Dauscher, Bertrand Lenoir

\section{To cite this version:}

Gilles Daigre, Patrick Gougeon, Philippe Gall, Régis Gautier, Olivier Guillou, et al.. Synthesis, crystal structure and high-temperature transport properties of the new cluster compound Rb2Mo15Se19. Journal of Solid State Chemistry, 2016, 237, pp.1-6. 10.1016/j.jssc.2016.01.006 . hal-01256844

HAL Id: hal-01256844

https://hal-univ-rennes1.archives-ouvertes.fr/hal-01256844

Submitted on 27 May 2016

HAL is a multi-disciplinary open access archive for the deposit and dissemination of scientific research documents, whether they are published or not. The documents may come from teaching and research institutions in France or abroad, or from public or private research centers.
L'archive ouverte pluridisciplinaire HAL, est destinée au dépôt et à la diffusion de documents scientifiques de niveau recherche, publiés ou non, émanant des établissements d'enseignement et de recherche français ou étrangers, des laboratoires publics ou privés. 


\section{ACCEPTED MANUSCRIPT}

Synthesis, Crystal Structure and High-Temperature Transport Properties of the New

\section{Cluster Compound $\mathrm{Rb}_{2} \mathrm{Mo}_{15} \mathrm{Se}_{19}$}

Gilles Daigre ${ }^{1}$, Patrick Gougeon ${ }^{1}$, Philippe Gall ${ }^{1}$, Régis Gautier ${ }^{1}$, Olivier Guillou ${ }^{1}$, JeanBaptiste Vaney², Christophe Candolfi ${ }^{2}$, Anne Dauscher ${ }^{2}$, Bertrand Lenoir ${ }^{2}$

${ }^{1}$ Sciences Chimiques de Rennes, UMR 6226 CNRS - INSA -Ecole Nationale Supérieure de Chimie de Rennes - Université de Rennes 1, Avenue du Général Leclerc, 35042 Rennes, France.

${ }^{2}$ Institut Jean Lamour, UMR 7198 CNRS - Université de Lorraine, Parc de Saurupt, CS 50840, 54011 Nancy, France

Corresponding author: patrick.gougeon@univ-rennes1.fr

\section{Abstract}

We report on the synthesis, crystal structure and high-temperature transport properties of $\mathrm{Rb}_{2} \mathrm{Mo}_{15} \mathrm{Se}_{19}$, a new member of the large family of $\mathrm{M}_{2} \mathrm{Mo}_{15} \mathrm{Se}_{19}(\mathrm{M}=\mathrm{In}, \mathrm{Tl}, \mathrm{K}, \mathrm{Ba})$ cluster compounds. Polycrystalline samples and single crystals of the ternary selenide $\mathrm{Rb}_{2} \mathrm{Mo}_{15} \mathrm{Se}_{19}$ were obtained by solid-state reactions. The trigonal crystal structure, successfully refined in space group $R \overline{3} c$ (No. 167) with unit-cell parameters $a=9.7618(1) \AA, c=58.254(1) \AA$ and $Z$ $=6$, was determined by single-crystal X-ray diffraction. The crystal structure contains $\mathrm{Mo}_{6} \mathrm{Se}_{8}{ }^{\mathrm{i}} \mathrm{Se}_{6}{ }^{\mathrm{a}}$ and $\mathrm{Mog}_{9} \mathrm{Se}_{11}{ }^{\mathrm{i}} \mathrm{Se}_{6}{ }^{\mathrm{a}}$ cluster units in equal proportion and separated from each other by large voids, which are filled up by $\mathrm{Rb}$ atoms. Measurements of the electrical resistivity, thermopower and thermal conductivity revealed that $\mathrm{Rb}_{2} \mathrm{Mo}_{15} \mathrm{Se}_{19}$ behaves as a $p$-type metal with relatively low electrical resistivity and thermopower. Despite its complex crystal 


\section{ACCEPTED MANUSCRIPT}

structure, the lattice thermal conductivity that amounts to $1.3 \mathrm{~W} \cdot \mathrm{m}^{-1} \cdot \mathrm{K}^{-1}$ at $300 \mathrm{~K}$ is significantly higher than in Ag-filled analogues, which provides possible guidelines to enhance its thermoelectric properties.

Keywords

Reduced molybdenum selenide, molybdenum clusters, rubidium, thermoelectric properties 


\section{Introduction}

Ternary chalcogenides composed of molybdenum atoms with low oxidation state are generally characterized by the occurrence of Mo-Mo bonds resulting in clearly defined bonded groups referred to as clusters. For instance, the tetrahedral $\mathrm{Mo}_{4}$ and the octahedral $\mathrm{Mo}_{6}$ clusters were first observed in compounds with general chemical formula $M \mathrm{Mo}_{4} X_{8}(M=$ A1, Ga; $X=\mathrm{S}$, Se, Te) [1] and $M_{x} \mathrm{Mo}_{6} X_{8}(M=3 d$ transition metals, Na, K, Ca, Sr, Ba, Sn, Pb or rare earth) [2]. The latter phases, known as Chevrel phases, have been extensively studied because of their outstanding physical properties [3,7]. Syntheses of compounds containing extended clusters such as $\operatorname{Mog}_{9} X_{11}$, which can be described as resulting from the condensation of a finite number (here two) of $\mathrm{Mo}_{6} X_{8}$ groups by face-sharing, were successfully prepared in the early 1980's. The condensed unit $\mathrm{Mo}_{9} X_{11}$ was first observed in the selenide $\operatorname{In}_{2} \mathrm{Mo}_{15} \mathrm{Se}_{19}$ [8] in which it alternates with $\mathrm{Mo}_{6} \mathrm{Se}_{8}$ clusters leaving large voids filled with In atoms. Subsequently, this combination of cluster units has been obtained in other ternaries with $\mathrm{K}$, $\mathrm{Ba}$ and $\mathrm{Tl}$ filling the voids in selenides and with $\mathrm{K}, \mathrm{Rb}$ and $\mathrm{Cs}$ in sulfides. These cluster compounds generally exhibit metallic properties and become superconducting with critical temperatures $\left(T_{\mathrm{c}}\right)$ ranging between 1.5 and $4.2 \mathrm{~K}$ depending on the nature of the filling element. The existence of the sulfides $\mathrm{Rb}_{2} \mathrm{Mo}_{15} \mathrm{~S}_{19}$ [9] and $\mathrm{Cs}_{2} \mathrm{Mo}_{15} \mathrm{~S}_{19}$ [10] motivated us to search for their Se analogues. While attempts to synthesize single-phase $\mathrm{Cs}_{2} \mathrm{Mo}_{15} \mathrm{Se}_{19}$ were unsuccessful and led to a mixture of the previously known compounds $\mathrm{Cs}_{2} \mathrm{Mo}_{12} \mathrm{Se}_{14}$ [11] and $\mathrm{Cs}_{3} \mathrm{Mo}_{15} \mathrm{Se}_{17}$ [12], we were able to obtain phase-pure samples of the new compound $\mathrm{Rb}_{2} \mathrm{Mo}_{15} \mathrm{Se}_{19}$.

Here, we report on the synthesis of single-crystalline and polycrystalline samples of $\mathrm{Rb}_{2} \mathrm{Mo}_{15} \mathrm{Se}_{19}$ and on its crystal structure determined through single crystal X-ray diffraction. As previous studies on the clusters compounds $\mathrm{Ag}_{x} \mathrm{Mog}_{9} \mathrm{Se}_{11}(3.4 \leq x \leq 3.9)[13,14]$, 
$\mathrm{Ag}_{3} \mathrm{In}_{2} \mathrm{Mo}_{15} \mathrm{Se}_{19}$ [15] and $\mathrm{Ag}_{2} \mathrm{Tl}_{2} \mathrm{Mog}_{9} \mathrm{Se}_{11}$ [16] have revealed interesting thermoelectric properties owing to their low ability to transport heat, the high-temperature transport properties of $\mathrm{Rb}_{2} \mathrm{Mo}_{15} \mathrm{Se}_{19}$ are also presented.

\section{Experimental}

\subsection{Synthesis and Crystal Growth}

In order to avoid any contamination by oxygen and moisture, all powders and starting reagents were kept and handled in a purified-argon-filled glovebox. $\mathrm{MoSe}_{2}, \mathrm{Rb}_{2} \mathrm{Mo}_{6} \mathrm{Se}_{6}$, and Mo, all in powder form, were used as starting materials for the solid-state syntheses. Prior to use, Mo powder was reduced under $\mathrm{H}_{2}$ flowing gas at $1000^{\circ} \mathrm{C}$ during ten hours in order to eliminate any traces of oxygen. $\mathrm{MoSe}_{2}$ was prepared by direct reaction of selenium with reduced Mo in a ratio 2:1 in an evacuated (ca. $10^{-2} \mathrm{~Pa}$ Ar residual pressure) and flame-baked silica tube, maintained at about $700^{\circ} \mathrm{C}$ during two days. $\mathrm{Rb}_{2} \mathrm{Mo}_{6} \mathrm{Se}_{6}$ was prepared in two steps. As a first step, $\mathrm{In}_{2} \mathrm{Mo}_{6} \mathrm{Se}_{6}$ was synthesized from a stoichiometric mixture of InSe, $\mathrm{MoSe}_{2}$ and Mo heated at $1000^{\circ} \mathrm{C}$ in evacuated sealed silica tube for $36 \mathrm{~h}$. The second step was an ion exchange reaction of $\mathrm{In}_{2} \mathrm{Mo}_{6} \mathrm{Se}_{6}$ with $\mathrm{RbCl}$ at $800^{\circ} \mathrm{C}$. For the latter, powders of $\mathrm{In}_{2} \mathrm{Mo}_{6} \mathrm{Se}_{6}$ and $\mathrm{RbCl}$ in a ratio of about 1:2.5 were mixed and then cold pressed. The pellet was subsequently sealed under vacuum in a long silica tube. The end of tube containing the pellet was placed in a furnace with about $5 \mathrm{~cm}$ of the other end out from the furnace, kept at nearly room temperature. The furnace was heated at $800^{\circ} \mathrm{C}$ for $48 \mathrm{~h}$. After reaction, white crystals of InCl were observed at the cool end of the tube. All starting reagents were found monophasic on the basis of their powder X-ray diffraction patterns. Phase-pure polycrystalline samples of $\mathrm{Rb}_{2} \mathrm{Mo}_{15} \mathrm{Se}_{19}$ were prepared from the required stoichiometric 


\section{ACCEPTED MANUSCRIPT}

mixture of $\mathrm{Rb}_{2} \mathrm{Mo}_{6} \mathrm{Se}_{6}$, Mo, and $\mathrm{MoSe}_{2}$ heated at $1300^{\circ} \mathrm{C}$ during $40 \mathrm{~h}$ in a molybdenum crucible sealed under a low argon pressure using an arc-welding system. Single crystals of $\mathrm{Rb}_{2} \mathrm{Mo}_{15} \mathrm{Se}_{19}$ were obtained by heating a powdered sample at $1750^{\circ} \mathrm{C}$ for $1 \mathrm{~h}$, then cooled to $1000^{\circ} \mathrm{C}$ at $100^{\circ} \mathrm{C} \cdot \mathrm{h}^{-1}$ and finally furnace cooled to room temperature.

\subsection{Hot Uniaxial Pressing (HUP)}

The obtained polycrystalline ingots of $\mathrm{Rb}_{2} \mathrm{Mo}_{15} \mathrm{Se}_{19}$ were finely ground into fine powders and densified by HUP carried out under vacuum (about $10^{-2} \mathrm{mbar}$ ). The pressing conditions were the following: the pressure was applied from the beginning of the temperature increase $\left(8^{\circ} \mathrm{C} \cdot \mathrm{min}^{-1}\right)$ to the end of the high-temperature dwell. Typical quantities of $5 \mathrm{~g}$ of $\mathrm{Rb}_{2} \mathrm{Mo}_{15} \mathrm{Se}_{19}$ powders were introduced into a graphite die $(\varnothing 12 \mathrm{~mm})$ previously coated with boron nitride. The applied load was $50 \mathrm{MPa}$ at the beginning of the heating step and was gradually increased to $85 \mathrm{MPa}$ when the sintering temperature $\left(1300^{\circ} \mathrm{C}\right)$ was reached. The dwell time was $2 \mathrm{~h}$ for all experiments. The density of the pellets (determined by weight and sample dimensions) was calculated to be around 95\% of the theoretical density from crystallographic data.

\subsection{Single Crystal Structure Determination}

The X-ray diffraction data were collected on a Nonius Kappa CCD diffractometer using graphite-monochromated Mo-K $\alpha$ radiation $(\lambda=0.71073 \AA)$ at room temperature. The COLLECT program package [17] was employed to establish the angular scan conditions ( $\varphi$ and $\omega$ scans) used in the data collection. The data set was processed using EvalCCD [18] for 


\section{ACCEPTED MANUSCRIPT}

the integration procedure. An absorption correction was applied using the description of the crystal faces and the analytical method described by de Meulenaar and Tompa [19]. Analysis of the data revealed that systematic extinctions were only consistent with the trigonal space groups $R \overline{3} c$ and $R 3 c$. The structure was successfully solved with the direct methods program SIR97 [20] and refined using SHELXL97 [21] in the centrosymmetric $R \overline{3} c$ space group. Refinement of the occupancy factor of the Rb site indicated a full occupation of the cationic site. Crystallographic data and X-ray structural analysis for the $\mathrm{Rb}_{2} \mathrm{Mo}_{15} \mathrm{Se}_{19}$ compound are summarized in Table 1. The final atomic coordinates and the equivalent isotropic displacement parameters are gathered in Table 2, and selected interatomic distances are listed

in Table 3. Further details of the crystal structure investigation can be obtained from the Fachinformationszentrum Karlsruhe, 76344 Eggenstein-Leopoldshafen, Germany, (fax: (49) 7247-808-666; e-mail: crysdata@fiz.karlsruhe.de) on quoting the depository number CSD430265.

\subsection{Structural and chemical characterizations}

Phase purity of the polycrystalline specimen was determined by powder X-ray diffraction (PXRD) using a D8 Bruker Advance diffractometer equipped with a LynxEye detector (CuK $\alpha_{1}$ radiation). Chemical characterization was carried out on a consolidated bulk piece by scanning electron microscopy (SEM) and energy dispersive X-ray spectroscopy (EDXS) elemental mapping using a Quanta 650 FEG (FEI).

\subsection{High-temperature transport properties}




\section{ACCEPTED MANUSCRIPT}

Electrical resistivity $\rho$ and thermopower $\alpha$ were measured simultaneously between 300 and $700 \mathrm{~K}$ on bar-shaped samples $\left(\sim 1.5 \times 1.5 \times 8 \mathrm{~mm}^{3}\right)$ cut perpendicularly to the pressing direction using a ZEM-3 apparatus (Ulva-Riko). These measurements were performed under a low helium pressure. The thermal diffusivity $a$ was measured between 300 and $700 \mathrm{~K}$ on a disk-shaped sample ( $12 \mathrm{~mm}$ in diameter, $\sim 1 \mathrm{~mm}$ in thickness) cut parallel to the pressing direction with a Netzsch laser flash instrument (LFA 467) under continuous argon flow. In order to ensure a homogeneous signal absorption and emission on the respective surfaces, the sample was spray-coated with a thin layer of graphite prior to the measurement. The thermal conductivity $\kappa$ was determined via $\kappa=a C_{\mathrm{p}} d$ where $C_{p}$ is the specific heat and $d$ is the density. As a first approximation, $C_{p}$ was estimated using the Dulong-Petit law $C_{p}=3 N R$ with $N$ the number of atom per formula unit and $R$ the gas constant. The experimental density determined from the weight and the geometric dimensions of the consolidated pellet was used and considered temperature-independent. Measurement of the sound velocities was carried out at $300 \mathrm{~K}$ on a disk-shaped sample using a pulse-echo method. Longitudinal and transverse sound velocities were extracted from the data. Honey was used to improve the coupling between the ultrasonic transducers and the sample.

\section{Results and Discussion}

\subsection{Crystal Structure}

The title compound (Figure 1) is isostructural with $\mathrm{In}_{2} \mathrm{Mo}_{15} \mathrm{Se}_{19}$ [8]. Consequently, its crystal structure contains $\mathrm{Mo}_{6} \mathrm{Se}_{8}^{\mathrm{i}} \mathrm{Se}_{6}^{\mathrm{a}}$ and $\mathrm{Mog}_{9} \mathrm{Se}_{11}^{\mathrm{i}} \mathrm{Se}_{6}^{\mathrm{a}}$ cluster units in equal proportion 


\section{ACCEPTED MANUSCRIPT}

(Figure 2). The i-type ligands cap Mo triangular faces and the a-type ones are in apical positions for the external Mo atoms. The $\mathrm{Mo}_{6} \mathrm{Se}_{8}^{\mathrm{i}}{ }_{8} \mathrm{Se}_{6}^{\mathrm{a}}$ and $\mathrm{Moo}_{9} \mathrm{Se}_{11}^{\mathrm{i}} \mathrm{Se}_{6}^{\mathrm{a}}{ }_{6}$ cluster units are centred at the $6 a$ ( $D_{3}$ or 32 symmetry) and $6 b$ positions ( $S_{6}$ or -3 symmetry), respectively. The Mo1-Mo1 distances within the $\mathrm{Mo}_{6}$ clusters are 2.6823 (4) $\AA$ for the intra-triangle distances (distances within the $\mathrm{Mo}_{3}$ triangles formed by the Mo atoms related through the threefold axis) and 2.7632 (4) $\AA$ for the inter-triangle distances. The Mo-Mo distances within the Mog clusters are 2.6706 (4) and 2.6827 (5) $\AA$ for the intra-triangle distances between the Mo2 and Mo3 atoms, respectively, and 2.7188 (2) and 2.8017 (2) $\AA$ for those between the $\mathrm{Mo}_{3}$ triangles. A comparison of the different Mo-Mo distances with those observed in $\mathrm{Rb}_{2} \mathrm{Mo}_{15} \mathrm{~S}_{19}$ [9] shows that they only differ by at most $0.017 \AA$. The Se atoms bridge either one (atoms Se1, Se2, Se4 and Se5) or two (atom Se3) Mo triangular faces of the clusters. Moreover, atoms Se1 and Se2 are linked to a Mo atom of a neighboring cluster. The Mo-Se bond distances range from 2.5361 (4) to 2.6042 (3) $\AA$ within the $\mathrm{Mo}_{6} \mathrm{Se}_{8}$ unit and from 2.5346 (3) to 2.7115 (3) $\AA$ within the $\mathrm{Mog}_{9} \mathrm{Se}_{11}$ unit. Each $\mathrm{Mog}_{9} \mathrm{Se}_{11}$ unit is interconnected to six $\mathrm{Mo}_{6} \mathrm{Se}_{8}$ units (and vice versa) via Mo1-Se2 bonds (or Mo2-Se1 bonds) to form the three-dimensional MoSe framework. As a result of this arrangement, the shortest intercluster Mo1-Mo2 distance between the $\mathrm{Mo}_{6}$ and $\mathrm{Mo}_{9}$ clusters is 3.4441 (3) $\AA$, indicative of a weak metal-metal interaction. This value is larger than the value of 3.246 (2) $\AA$ observed for $\mathrm{Rb}_{2} \mathrm{Mo}_{15} \mathrm{~S}_{19}$, as expected from the larger size of the selenium atoms. The $\mathrm{Rb}$ cations are located in a pentacapped trigonal prismatic environment of Se atoms (Figure 3) with Rb-Se distances ranging from 3.2617 (3) to 3.8205 (4) Å. This Rb environment corresponds in fact to the Edshammar 11-polyhedron that occurs for example in interstitial $\mathrm{Ni}_{2} \mathrm{In}$ type structures [22]. In our case, the maximum torsion angle of the rhombic faces of the polyhedron is $6.7^{\circ}$.

\subsection{Phase purity}


Analysis of the powder X-ray diffraction pattern by the Le Bail method is illustrated in Figure 4 and indicates that the polycrystalline specimen is single phase within the level about 2\%. Two illustrative SEM images collected in backscattered electron (BSE) mode are shown in Figures 5a and 5b along with the corresponding elemental mapping. Both figures reveal that all the elements are homogeneously distributed with no noticeable secondary phases in the grains or precipitated at the grain boundaries. The chemical composition was determined by EDXS as $\mathrm{Rb}_{2.09} \mathrm{Mo}_{14.93} \mathrm{Se}_{18.98}$.

\subsection{High-temperature transport properties}

Previous theoretical studies have shown that the electronic band structure of Mo-cluster compounds is mainly dictated by the electronic structure of the cluster units. The cations inserted in the crystal structure donate their electron to the cluster framework and thus, determine the overall metallic electron count (MEC) of the structure. When the optimal MEC of the cluster units is reached, the compounds are charge balanced, resulting in semiconducting properties. In the present case, the optimal MEC of the $\mathrm{Mo}_{6}$ and $\mathrm{Mo}_{9}$ clusters are 24 and 36, respectively, so that charge balance is achieved when the total MEC equals to 60 [23-25]. On this basis, $\mathrm{Rb}_{2} \mathrm{Mo}_{15} \mathrm{Se}_{19}$ is expected to be isoelectronic with $\mathrm{In}_{2} \mathrm{Mo}_{15} \mathrm{Se}_{19}$ due to the monovalent character of Rb leading to a similar total MEC of 54 [15]. The lack of six electrons to reach the optimal MEC should thus give rise to $p$-type metallic properties. The temperature dependences of the electrical resistivity and thermopower, shown in Figure 6 are consistent with this simple electron-counting rule. Indicative of degenerate transport, the very low $\alpha$ values increase linearly with increasing temperature to reach a maximum of $35 \mu \mathrm{V} . \mathrm{K}^{-1}$ 


\section{ACCEPTED MANUSCRIPT}

at $700 \mathrm{~K}$. The measured positive values indicate that holes are the dominant charge carriers as already observed in the Ag- and In-based analogues [15]. Despite a high carrier concentration expected in this metallic system, the $\rho$ values are high and increase from $42 \mu \Omega$.m at $300 \mathrm{~K}$ up to $75 \mu \Omega . \mathrm{m}$ at $700 \mathrm{~K}$, suggesting intrinsically very low hole mobility.

The total thermal conductivity of $\mathrm{Rb}_{2} \mathrm{Mo}_{15} \mathrm{Se}_{19}$ increases smoothly from $1.5 \mathrm{~W} \mathrm{~m}^{-1} \mathrm{~K}^{-1}$ at $300 \mathrm{~K}$ to $2.0 \mathrm{~W} \mathrm{~m}^{-1} \mathrm{~K}^{-1}$ at $700 \mathrm{~K}$ (Figure 7 ). The electronic contribution $\kappa_{\mathrm{e}}$ to the thermal conductivity has been estimated using the Wiedemann-Franz law $\kappa_{\mathrm{e}}=L T / \rho$ with a Lorenz number $L$ equal to $L_{0}=2.45 \times 10^{-8} \mathrm{~V}^{2} \mathrm{~K}^{-2}$ for a degenerate electron gas. The lattice thermal conductivity $\kappa_{\mathrm{L}}=\kappa-\kappa_{\mathrm{e}}$ is low, of the order of $1.3 \mathrm{~W} \mathrm{~m}^{-1} \mathrm{~K}^{-1}$ at $300 \mathrm{~K}$ (Figure 7). Yet, these values remain higher than those achieved in the Ag-based analogue [15], evidencing the beneficial influence of the Ag atoms on low thermal transport in this family of compounds. This difference can be appreciated when comparing $\kappa_{L}$ to the minimum thermal conductivity $\kappa_{m}$ calculated within the model developed by Cahill et al. [26]. This model assumes that this value is reached when the phonon mean free path is reduced to its physically-meaningful lowest value of $\lambda / 2$ for a phonon of wavelength $\lambda$. The high-temperature limit of $\kappa_{m}$ is then expressed as

$$
\kappa_{m}=\frac{1}{2}\left(\frac{\pi}{6}\right)^{1 / 3} k_{B} V^{-2 / 3}\left(2 v_{T}+v_{L}\right)
$$

where $V$ is the average volume per atom estimated from crystallographic data. The longitudinal and transverse sound velocities were found to be $v_{L}=2489 \mathrm{~m} \mathrm{~s}^{-1}$ and $v_{T}=1472$ $\mathrm{m} \mathrm{s}^{-1}$, respectively. These values correspond to a Debye temperature of $178 \mathrm{~K}$ via 


$$
\begin{aligned}
& \text { ACCEPTED MANUSCRIPT } \\
& \qquad \theta_{D}=\frac{v_{m} \hbar}{k_{B}}\left(\frac{6 \pi^{2}}{V}\right)^{1 / 3}
\end{aligned}
$$

where $v_{m}$ is the average speed of sound calculated from

$$
\frac{3}{v_{m}^{3}}=\frac{2}{v_{T}^{3}}+\frac{1}{v_{L}^{3}}
$$

The $\kappa_{\mathrm{L}}$ values remain higher than the predicted $\kappa_{m}\left(\sim 0.4 \mathrm{~W} \mathrm{~m}^{-1} \mathrm{~K}^{-1}\right)$ between 300 and $700 \mathrm{~K}$ (Figure 7). Unlike $\mathrm{Rb}_{2} \mathrm{Mo}_{15} \mathrm{Se}_{19}, \kappa_{L}$ is close to $\kappa_{m}$ in $\mathrm{Ag}_{3} \mathrm{In}_{2} \mathrm{Mo}_{15} \mathrm{Se}_{19}$ [15] suggesting that introducing $\mathrm{Ag}$ in the crystal structure of $\mathrm{Rb}_{2} \mathrm{Mo}_{15} \mathrm{Se}_{19}$ may prove to be an effective strategy in further reducing $\kappa_{L}$.

\section{Summary and Conclusion}

The novel reduced molybdenum selenide $\mathrm{Rb}_{2} \mathrm{Mo}_{15} \mathrm{Se}_{19}$ has been successfully synthesized by solid-state reaction at $1300^{\circ} \mathrm{C}$ in a sealed molybdenum crucible. Likewise $\mathrm{In}_{2} \mathrm{Mo}_{15} \mathrm{Se}_{19}$ [8], its crystal structure contains octahedral $\mathrm{Mo}_{6}$ and bioctahedral $\mathrm{Mo}_{9}$ clusters in equal proportion forming $\mathrm{Mo}_{6} \mathrm{Se}_{8}^{\mathrm{i}} \mathrm{Se}_{6}^{\mathrm{a}}$ and $\mathrm{Mog}_{9} \mathrm{Se}_{11}^{\mathrm{i}} \mathrm{Se}_{6}^{\mathrm{a}}$ cluster units with their Se environments. The latter two units are separated from each other by large Se voids which are filled up by eleven-coordinate $\mathrm{Rb}$ atoms. In agreement with the metal electron count, $\mathrm{Rb}_{2} \mathrm{Mo}_{15} \mathrm{Se}_{19}$ behaves as a $p$-type metal with relatively low electrical resistivity and low thermopower. The lattice thermal conductivity is very low and temperature-independent between 300 and $700 \mathrm{~K}$. Despite the large number of atoms per unit cell $(N=216)$, the $\kappa_{L}$ values do not approach the minimum thermal conductivity in this temperature range. The fact 


\section{ACCEPTED MANUSCRIPT}

that adding $\mathrm{Ag}$ atoms in the $\mathrm{In}_{2} \mathrm{Mo}_{15} \mathrm{Se}_{19}$ analogue [15] results in semiconducting-like properties and significantly lowers $\kappa_{L}$ down to $\kappa_{m}$ provides a possible route for optimizing the thermoelectric properties of $\mathrm{Rb}_{2} \mathrm{Mo}_{15} \mathrm{Se}_{19}$. 


\section{ACCEPTED MANUSCRIPT}

\section{References}

[1] J. M. Vandenberg and D. Brasen, J. Solid State Chem. 14 (1975) 203.

[2] R. Chevrel, M. Sergent, J. Prigent, J. Solid State Chem. 3 (1971) 515.

[3] Ø. Fischer, Appl. Phys. 16 (1978) 1.

[4] O. Pena, M. Sergent, Prog. Solid State Chem. 19 (1989) 165.

[5] D. H. Douglass (ed.), in Superconductivity in $d$ - and f-band Metals (Plenum Press, New York, 1986).

[6] G. K. Shenoy, B. D. Dunlap, F. Y. Fradin (eds.), Ternary Superconductors (North Holland, New York, Amsterdam, Oxford, 1981).

[7] Ø. Fischer and M. B. Maple (eds.), Topics in Current Physics, vol. 32/34: Superconductivity in Ternary Compounds, Tomes I and II. (Springer, Berlin, Heidelberg, New York, 1982).

[8] M. Potel, R. Chevrel, M. Sergent, Acta Cryst. B37 (1981) 1007

[9] S. Picard, J.-Y. Saillard, P. Gougeon, H. Noel, M. Potel, J. Solid State Chem. 155 (2000) 417.

[10] S. Picard, D. Salloum, P. Gougeon, M. Potel, Acta Cryst. C60 (2004) i61.

[11] P. Gougeon, M. Potel, J. Padiou, M. Sergent, Mater. Res. Bull. 22 (1988) 1087.

[12] P. Gougeon, M. Potel, M. Sergent, Acta Cryst. C45 (1989) 1413.

[13] T. Zhou, B. Lenoir, M. Colin, A. Dauscher, P. Gall, P. Gougeon, M. Potel, E. Guilmeau, Appl. Phys. Lett. 98 (2011) 162106.

[14] T. Zhou, M. Colin, C. Candolfi, C. Boulanger, A. Dauscher, E. Santava, J. Hejtmanek, P. Baranek, R. Al Rahal Al Orabi, M. Potel, B. Fontaine, P. Gougeon, R. Gautier, B. Lenoir, Chem. Mater. 26 (2014) 4765.

[15] P. Gougeon, P. Gall, R. Al Rahal Al Orabi, B. Fontaine, R. Gautier, M. Potel, T. Zhou, B. Lenoir, M. Colin, C. Candolfi, A. Dauscher, Chem. Mater. 24 (2012) 2899. 


\section{ACCEPTED MANUSCRIPT}

[16] R. Al Rahal Al Orabi, P. Gougeon, P. Gall, B. Fontaine, R. Gautier, M. Colin, C.

Candolfi, A. Dauscher, J. Hejtmanek, B. Malaman, B. Lenoir, Inorg. Chem. 53 (2014) 11699.

[17] Nonius BV, COLLECT, Data Collection Software, Nonius BV, 1999.

[18] A. J. M. Duisenberg, Reflections on area detectors, Ph.D. Thesis, Utrecht, 1998.

[19] J. de Meulenaar, H. Tompa, Acta Crystallogr. Sect. A: Found. Crystallogr. 19 (1965) 1014.

[20] A. Altomare, M. C. Burla, M. Camalli, G. L. Cascarano, C. Giacovazzo, A. Guagliardi, A. G. G. Moliterni, G. Polidori, R. Spagna, J. Appl. Cryst. 32 (1999) 115.

[21] G. M. Sheldrick, SHELXL97, Program for the Refinement of Crystal Structures, University of Göttingen, Germany, 1997.

[22] L.-E. Edshammar, 'X-Ray Studies on Binary Alloys of Aluminium with Platinum Metals', Dissertation, University of Stockholm 1969.

[23] T. Hughbanks, R. Hoffmann, J. Am. Chem. Soc. 105 (1983) 1150.

[24] R. Gautier, P. Gougeon, J.-F. Halet, M. Potel, J.-Y. Saillard, J. Alloys Compd. 262-263 (1997) 311.

[25] P. Gougeon, R. Al Rahal Al Orabi, R. Gautier, M. Potel, Acta Crystallogr., Sect. C: Cryst. Struct. Commun. C68 (2012) i25-i28.2) i25-i28

[26] D. G. Cahill, S. K. Watson, R. O. Pohl, Phys. Rev. B 46 (1992) 6131. 


\section{Tables}

Table 1. Single-crystal data collection and structure refinement of $\mathrm{Rb}_{2} \mathrm{Mo}_{15} \mathrm{Se}_{19}$ at $300 \mathrm{~K}$.

\begin{tabular}{|c|c|}
\hline Empirical formula & $\mathrm{Rb}_{2} \mathrm{Mo}_{15} \mathrm{Se}_{19}$ \\
\hline Molar mass (g.mol ${ }^{-1}$ ) & 3110.88 \\
\hline Symmetry & Trigonal \\
\hline Space group & $R \overline{3} c$ \\
\hline$a(\AA)$ & $9.7618(1)$ \\
\hline$c(\AA)$ & $58.254(1)$ \\
\hline$V\left(\AA^{3}\right)$ & $4807.5(1)$ \\
\hline $\mathrm{Z}$ & 6 \\
\hline$\rho\left(\mathrm{g} . \mathrm{cm}^{-3}\right)$ & 6.446 \\
\hline Crystal color and habit & black, irregular \\
\hline Crystal size $\left(\mathrm{mm}^{3}\right)$ & $0.189 \times 0.107 \times 0.101$ \\
\hline Radiation & Mo K $\alpha$ \\
\hline$\theta$ range $\left(^{\circ}\right)$ & $3.69-37.95$ \\
\hline $\begin{array}{l}\text { Absorption coefficient } \\
\left(\mathrm{mm}^{-1}\right)\end{array}$ & 30.239 \\
\hline Limiting indices & $-16 \leq h \leq 16,-16 \leq k \leq 16,-92 \leq l \leq 100$ \\
\hline Reflections collected/unique & 43702 / 2913 \\
\hline$R$ (int) & 0.0606 \\
\hline Absorption correction & analytical \\
\hline Max./min. transmission & 0.1623 / 0.0369 \\
\hline Data/restraints/parameters & 2913 / 0 / 57 \\
\hline$R$ indices $[I>2 \sigma(I)]$ & $\mathrm{R} 1=0.0240, w \mathrm{R} 2=0.0437$ \\
\hline Extinction coefficient & $0.000053(3)$ \\
\hline $\begin{array}{l}\text { Largest diff. peak and hole } \\
\left(\mathrm{e} \AA^{-3}\right)\end{array}$ & 2.966 and -1.515 \\
\hline Goodness-of-fit on $F^{2}$ & 1.13 \\
\hline
\end{tabular}




\section{ACCEPTED MANUSCRIPT}

Table 2. Fractional atomic coordinates and equivalent isotropic thermal displacement parameters $\left(\AA^{2}\right)$.

$\begin{array}{ccccc}\text { Atom } & x & y & z & U_{\text {eq }} \\ & & & & \\ \text { Mo1 } & 0.64707(3) & -0.51873(3) & 0.35297(2) & 0.00627(4) \\ \text { Mo2 } & 0.84734(3) & -0.16275(3) & 0.28925(2) & 0.00640(4) \\ \text { Mo3 } & 0.84134(3) & 0.0000 & 0.2500 & 0.00569(5) \\ \text { Se1 } & 0.62920(3) & -0.38011(3) & 0.31678(2) & 0.00802(5) \\ \text { Se2 } & 0.64956(3) & -0.31096(3) & 0.38087(2) & 0.00909(5) \\ \text { Se3 } & 0.69327(4) & -0.30673(4) & 0.2500 & 0.00964(7) \\ \text { Se4 } & 0.6667 & -0.6667 & 0.38745(2) & 0.01141(9) \\ \text { Se5 } & 1.0000 & 0.0000 & 0.32382(2) & 0.00959(8) \\ \text { Rb } & 1.0000 & 0.0000 & 0.38646(2) & 0.02513(13)\end{array}$


Table 3. Selected Interatomic Distances (in $\AA$ ) for $\mathrm{Rb}_{2} \mathrm{Mo}_{15} \mathrm{Se}_{19}$.

\begin{tabular}{ll}
\hline Mo1-Mo1 & $2.6823(4)$ \\
Mo1-Mo1 & $2.7632(4)$ \\
Mo1-Se4 & $2.5361(4)$ \\
Mo1-Se1 & $2.5580(3)$ \\
Mo1-Se2 & $2.5896(3)$ \\
Mo1-Se1 & $2.6001(3)$ \\
Mo1-Se1 & $2.6042(3)$ \\
& \\
Mo2-Mo2 & $2.6706(4)$ \\
Mo2-Mo3 & $2.7188(2)$ \\
Mo3-Mo3 & $2.6827(5)$ \\
Mo3-Se2 (x2) & $2.5346(3)$ \\
Rb-Se3 (x3) & $3.8205(4)$ \\
\hline Rb-Se2 (x3) & $3.2617(3)$ \\
Rb-Se4 & $3.4616(9)$ \\
\hline Rb-Se5 & $3.6491(9)$ \\
\hline
\end{tabular}




\section{ACCEPTED MANUSCRIPT}

\section{Figure Captions}

Figure 1: View of $\mathrm{Rb}_{2} \mathrm{Mo}_{15} \mathrm{Se}_{19}$ along [110]. Thermal displacement ellipsoids are drawn at the 97\% probability level.

Figure 2: Plot showing the atom-numbering scheme and the interunit linkage of the $\mathrm{Mog}_{9} \mathrm{Se}_{11} \mathrm{Se}_{6}$ and $\mathrm{Mo}_{6} \mathrm{Se}_{8} \mathrm{Se}_{6}$ cluster units. Thermal displacement ellipsoids are drawn at the 97\% probability level.

Figure 3: Se environment of the $\mathrm{Rb}^{+}$cation.

Figure 4: Observed (black circles), calculated (red line) and difference profile (line below) for the refinement of $\mathrm{Rb}_{2} \mathrm{Mo}_{15} \mathrm{Se}_{19}$ in profile-matching mode $(\lambda=1.5406 \AA)$. All reflections could be indexed using the crystal structure determined from single-crystal refinements. The ticks mark the calculated position of the reflections.

Figure 5: BSE images of the surface of the polycrystalline sample along with the X-ray elemental mapping collected at a scale of $50 \mu \mathrm{m}$ (a) and $6 \mu \mathrm{m}$ (b).

Figure 6: Temperature dependence of the electrical resistivity $\rho(\bullet)$ and the thermopower $\alpha$ $(\mathbf{a})$. 


\section{ACCEPTED MANUSCRIPT}

Figure 7: Total thermal conductivity $\kappa(\bullet)$, lattice thermal conductivity $\kappa_{L}(\boldsymbol{\Delta})$ and electronic thermal conductivity $\kappa_{e}(\boldsymbol{\square})$ as a function of temperature. The horizontal solid black line stands for the estimated theoretical minimum of the thermal conductivity $\kappa_{m}$ calculated using Eq.(1). 


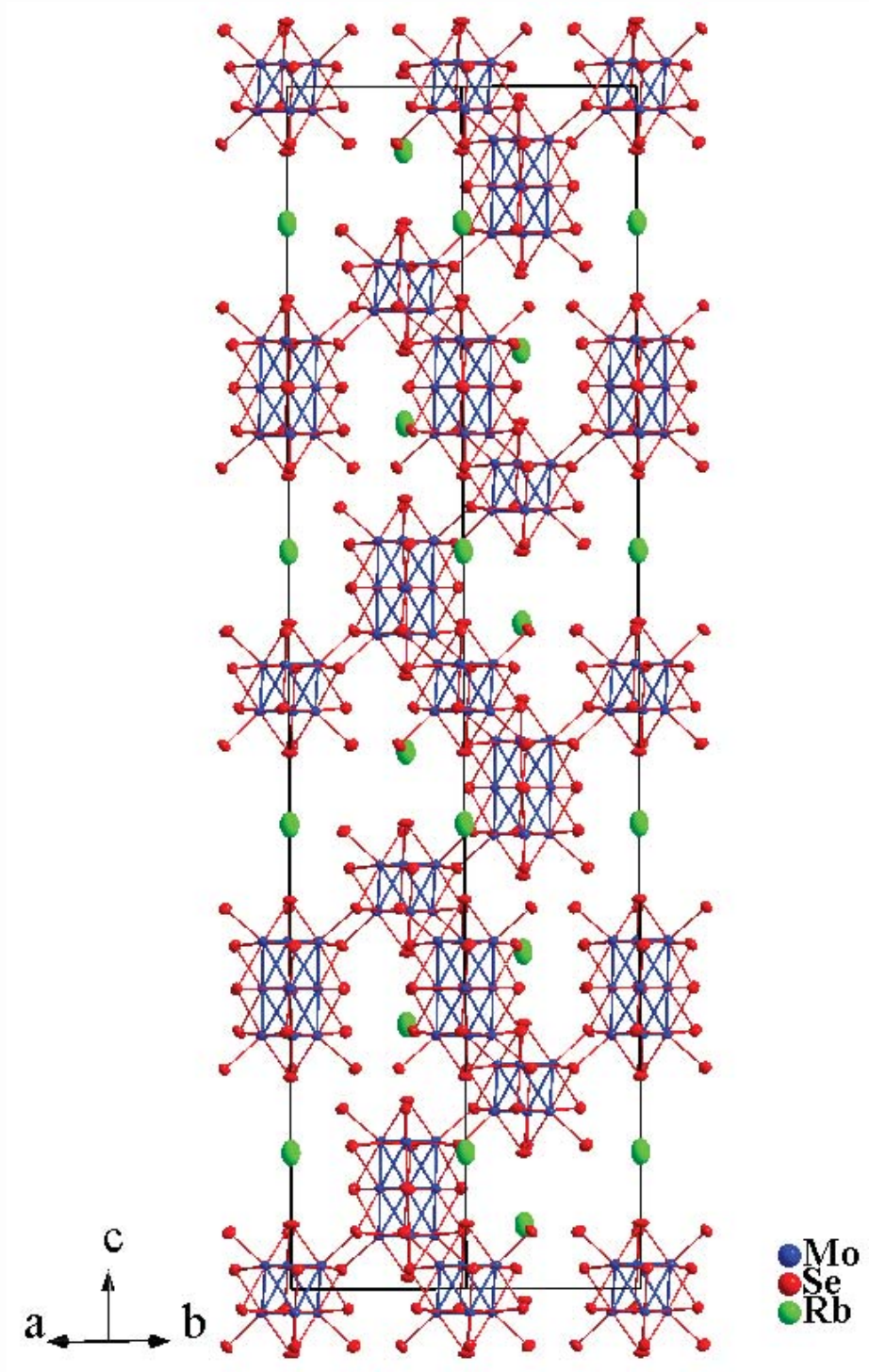

Figure 1 


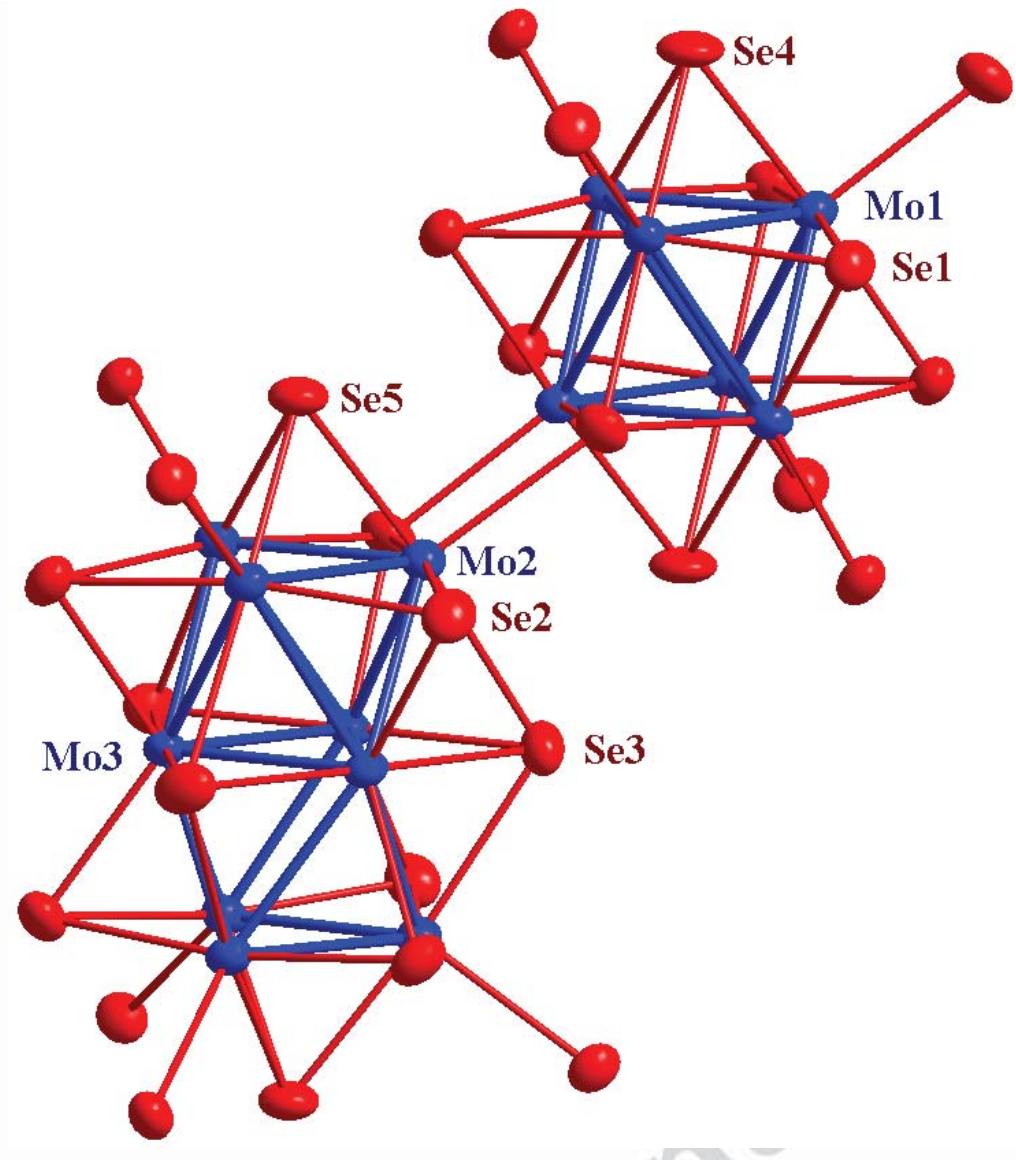

Figure 2 


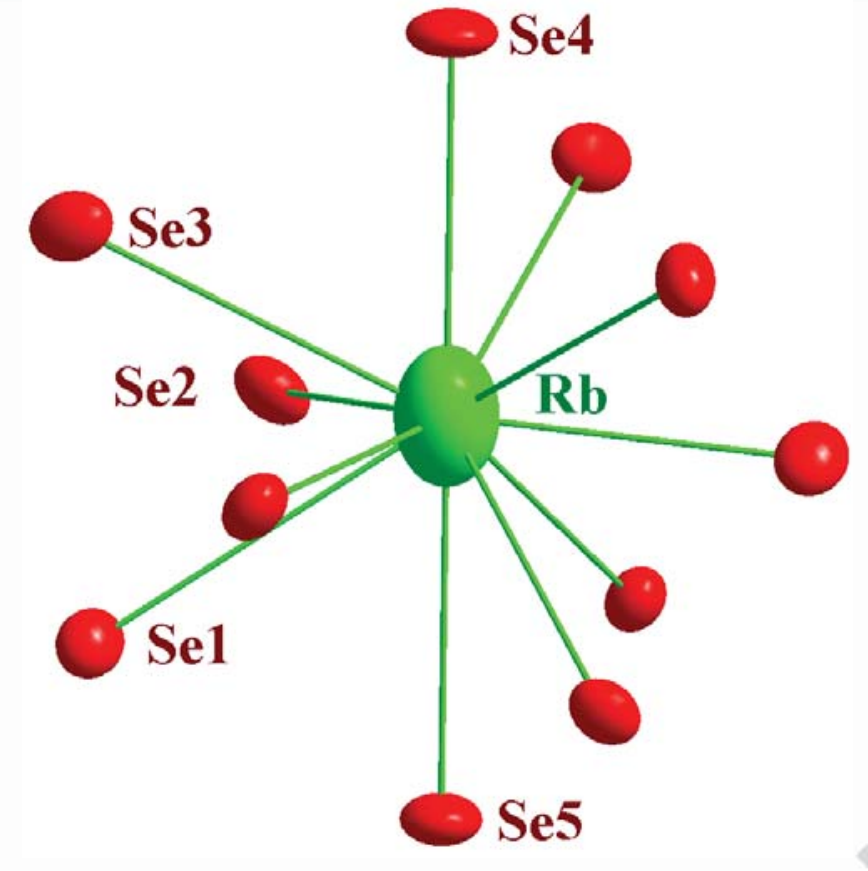

Figure 3 


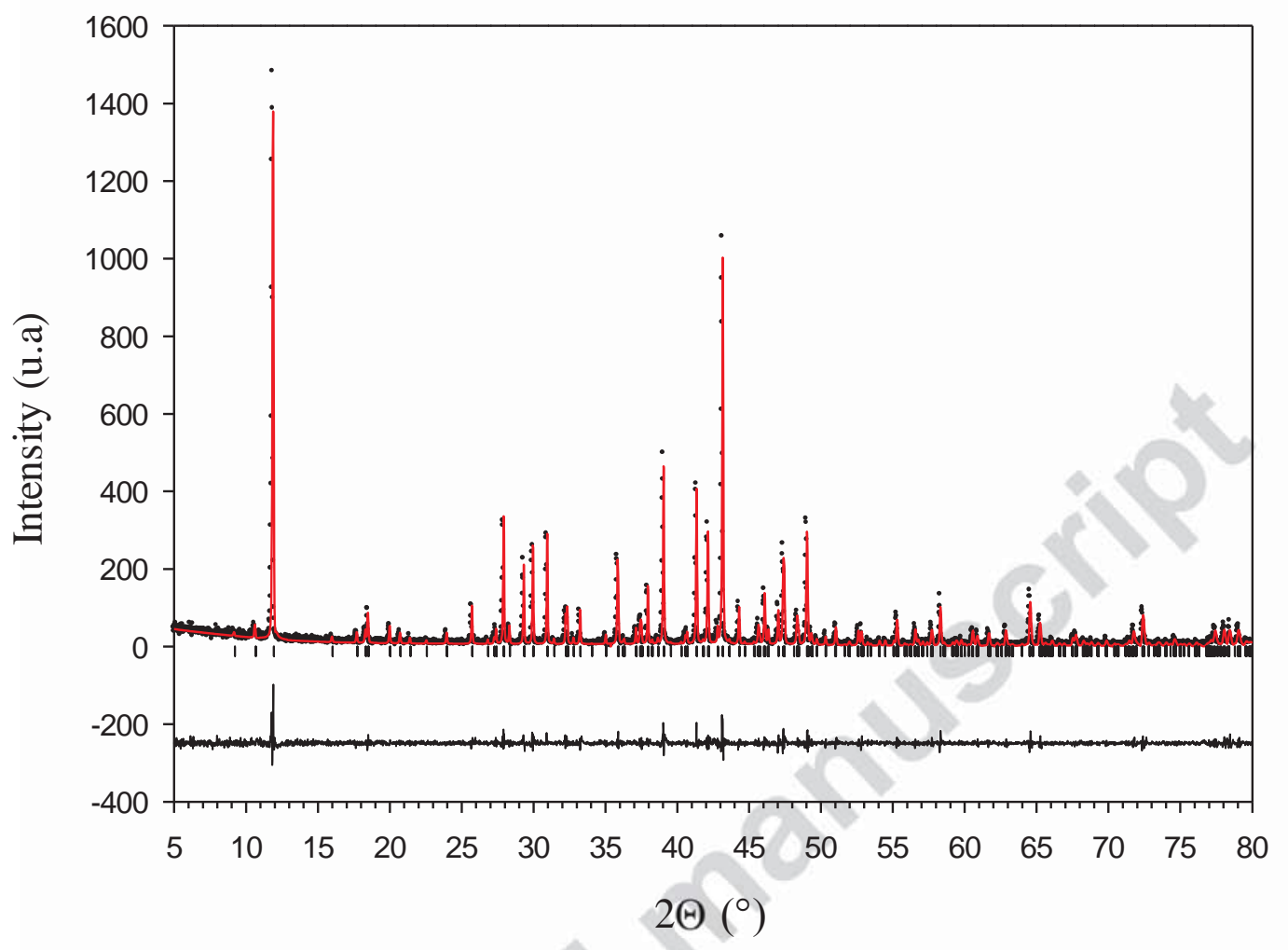

Figure 4 
a)
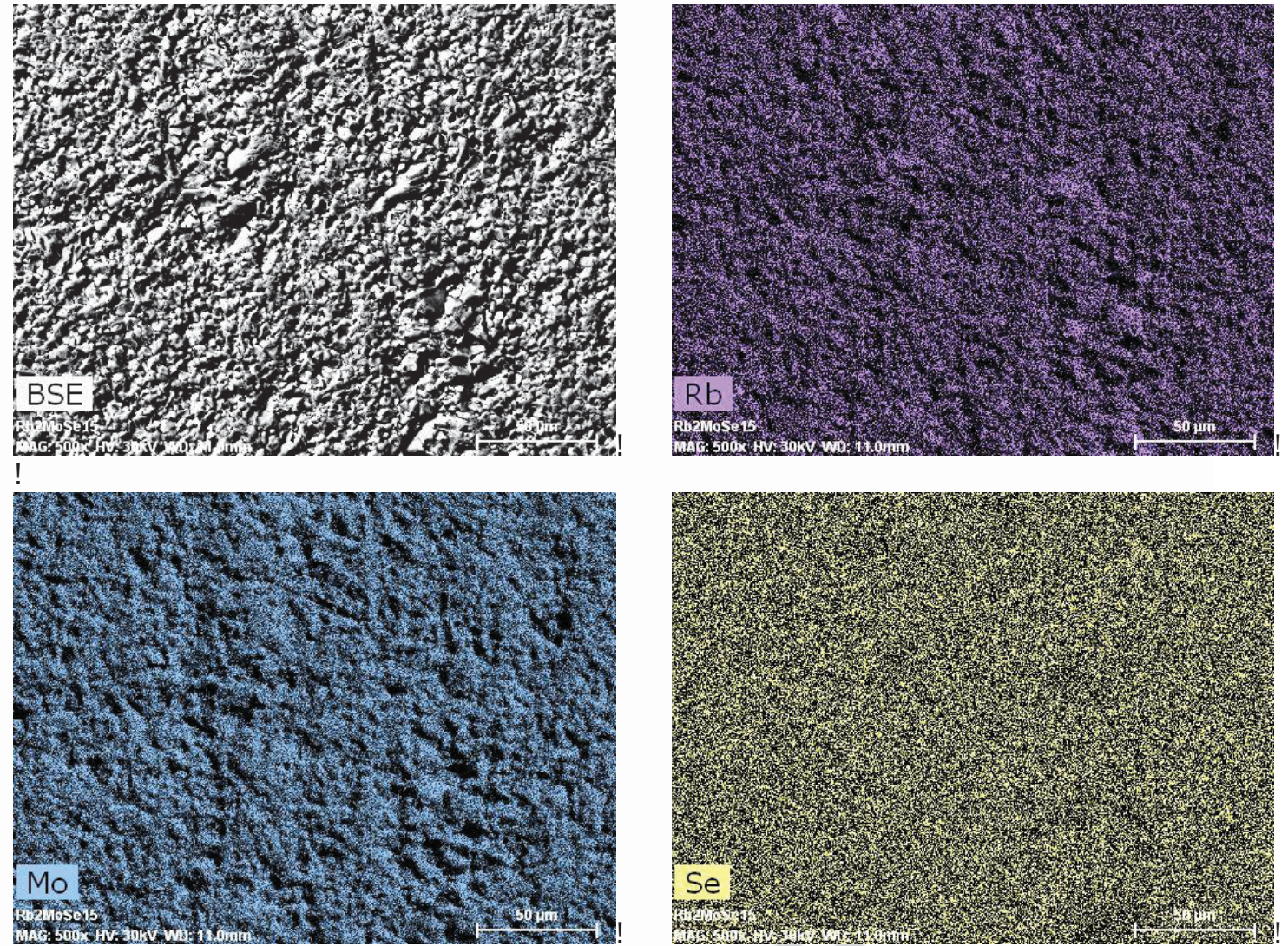

b)
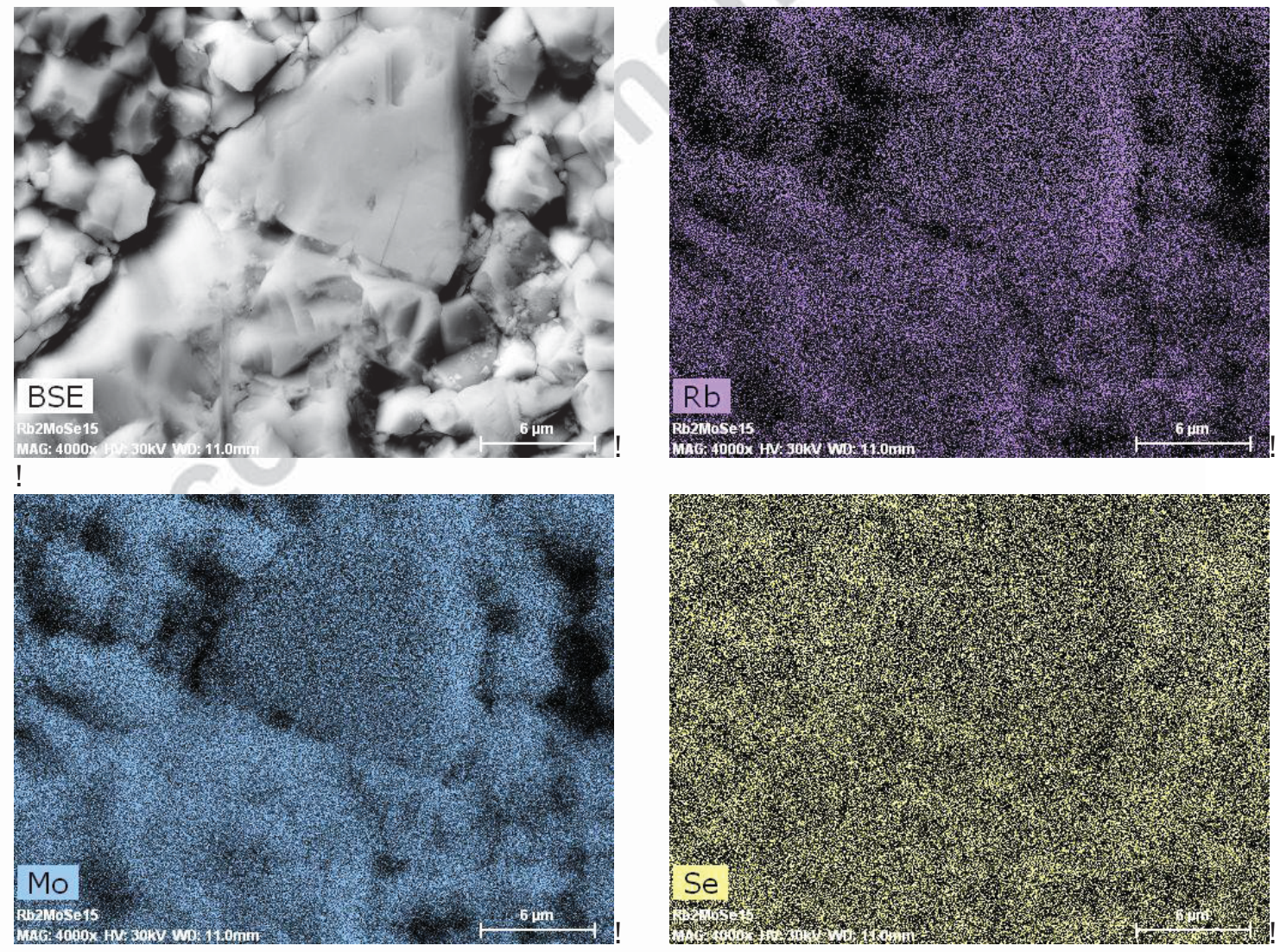

Figure 5 


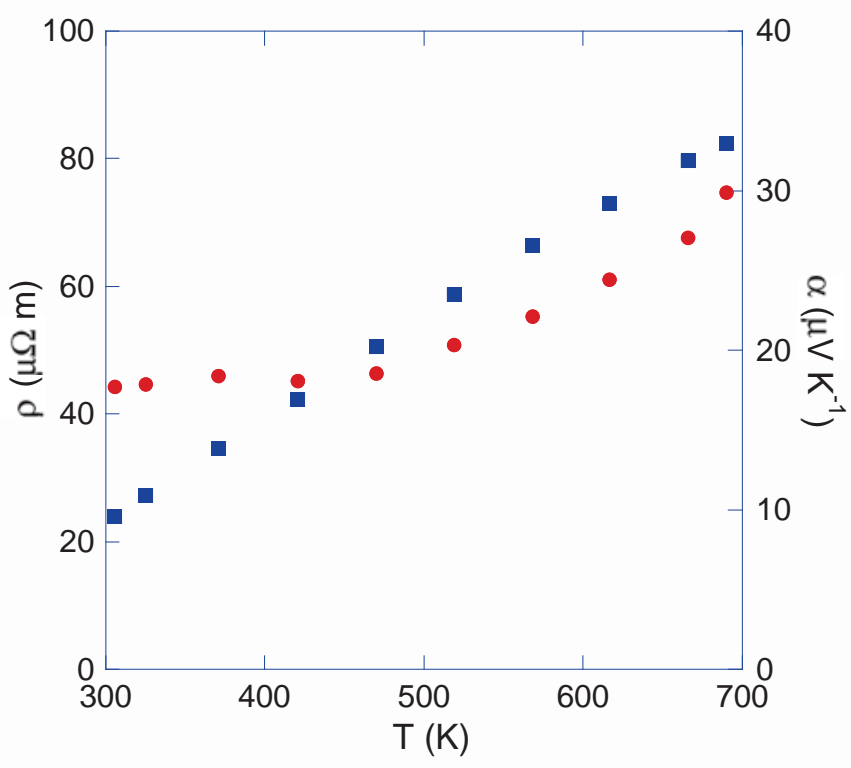

Figure 6 

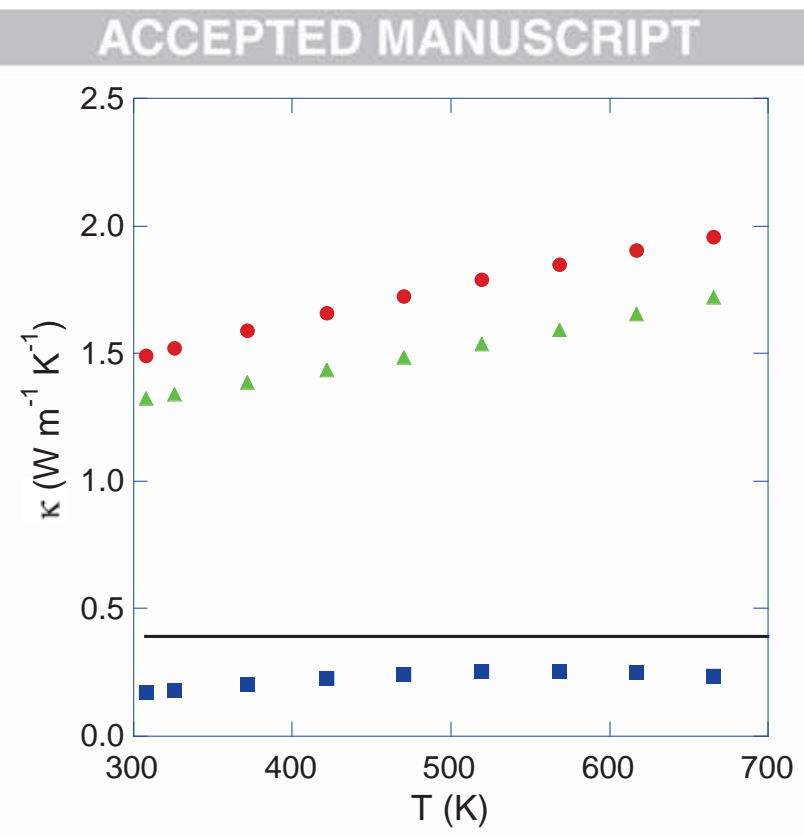

Figure 7 


\section{ACCEPTED MANUSCRIPT}

\section{Graphical abstract}

The crystal structure of the new cluster compound $\mathrm{Rb}_{2} \mathrm{Mo}_{15} \mathrm{Se}_{19}$ contains octahedral $\mathrm{Mo}_{6}$ and bioctahedral $\mathrm{Mog}_{9}$ clusters in equal proportion forming $\mathrm{Mo}_{6} \mathrm{Se}_{8}{ }^{\mathrm{i}} \mathrm{Se}_{6}{ }^{\mathrm{a}}$ and $\mathrm{Mog}_{9} \mathrm{Se}_{11}{ }^{\mathrm{i}} \mathrm{Se}_{6}{ }^{\mathrm{a}}$ cluster units separated from each other by large voids filled by Rb atoms. Measurements of the electrical resistivity, thermopower and thermal conductivity revealed that $\mathrm{Rb}_{2} \mathrm{Mo}_{15} \mathrm{Se}_{19}$ behaves as a p-type metal with relatively low electrical resistivity and thermopower.

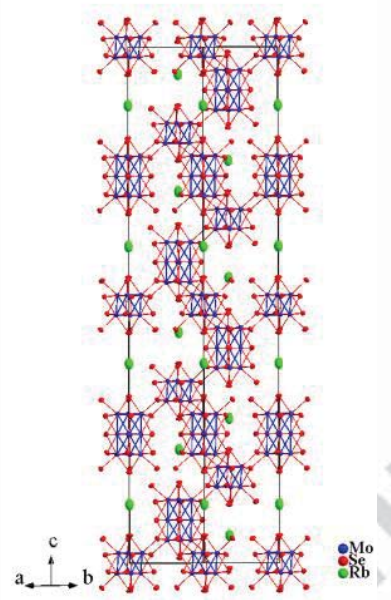

\section{Highlights}

- Successful synthesis of single-crystalline and polycrystalline $\mathrm{Rb}_{2} \mathrm{Mo}_{15} \mathrm{Se}_{19}$

- Crystal structure contains octahedral and bioctahedral clusters in equal proportion

- $\mathrm{Rb}_{2} \mathrm{Mo}_{15} \mathrm{Se}_{19}$ is a $p$-type metal with low electrical resistivity and thermopower

- The lattice thermal conductivity is higher compared to Ag-filled analogues 